M.I. Baranov

\title{
POWER DESCRIPTIONS OF A STORM CLOUD OF TROPOSPHERE OF EARTH: FEATURES OF THEIR CALCULATION AND APPLIED UTILIZATION
}

Purpose. Implementation of calculation estimation of such basic power descriptions of the system is a «storm cloud - earth», as total charge of $q_{\Sigma}$, electric potential of $\varphi_{r}$, electric energy of $W_{0}$ and amplitude-temporal parameters $(A T P)$ of pulse current $i_{L}(t)$ in the channel of a long air spark discharge of cloud on earth. Methodology. Electrophysics bases of technique of high voltages and large currents, theoretical bases of the electrical engineering, theoretical electrophysics, theory of the electromagnetic field and technique of the strong electric and magnetic fields. Results. The results of calculation estimation of basic power descriptions are resulted in the overhigh voltage electrophysics calculation system a "storm cloud - earth". To such descriptions of a storm cloud behave: total electric charge of $q_{\Sigma}$, concentrated in a storm cloud of spherical form of the set volume with the shallow dispersible negatively charged including as particulate dielectric matters the set by an middle closeness; electric potential of $\varphi_{r}$ is in the spherical volume of a storm cloud of the set size; electric energy of $W_{0}$, accumulated in the spherical volume of a storm cloud of the set radius of $R_{0}$; PTP (amplitude of $I_{m L}$ and duration of $\tau_{p}$ at level $0.5 I_{m L}$ ) of aperiodic impulse of current $i_{L}(t)$ of linear lightning in the plasma channel of a long air spark digit of a storm cloud on earth. The ground of possibility of the use is given in close practical calculations in place of the real storm cloud of the simplified calculation model of a storm cloud, containing the spherical volume of $V_{0}$ by the radius of $R_{0}$ is shown that at $R_{0} \approx 985 \mathrm{~m}$ and accordingly $V_{0} \approx 4 \cdot 10^{9} \mathrm{~m}^{3}$ in the examined model of a storm cloud his indicated power descriptions arrive at the followings numeral values: charge of $q_{\Sigma} \approx-55.6 C$, potential on the outward surface of cloud of $\varphi_{R} \approx-506 \mathrm{MV}$, electric energy of $W_{0} \approx 14.1 \mathrm{GJ}$ in a cloud and amplitude of aperiodic impulse of current of $I_{m L} \approx-262.1 \mathrm{KA}$ at duration of his flowing $\tau_{p} \approx 142.4 \mu \mathrm{s}$ in the plasma channel of a long air spark digit of cloud on earth. This calculation information well correlates with the known experimental information, characteristic for the short shots of lightning in surface objects. The receive results will be instrumental in possibility of prognostication of a sticky storm wicket specialists at presence of only minimum initial information about a storm cloud in earthly troposphere. Originality. First at the analysis of a storm situation in troposphere of Earth offered approach, related to bringing the real storm cloud over the volume of $V_{0}$ to an equivalent on volume spherical storm cloud by the radius of $R_{0}$, for which will apply the physical and mathematical vehicle of analysis of flowings in him electrophysics processes developed an author. Practical value. Application of the in practice calculation findings will allow to deepen scientific and technical knowledge in area of nature of atmospheric electricity, will be instrumental in further development of physics of linear lightning and successful decision of global problem of protecting from lightning of surface objects and auxiliary them personnel. References 12, figures 2.

Key words: atmospheric electricity, storm cloud, accumulated charge, electric potential and energy of cloud, current in the channel of discharge of cloud on earth, calculation, experimental information.

Приведены результаты расчетной оценки основных энергетических характеристик сверхвысоковольтной системы «грозовое облако-земля", содержащей сплошную заряженную сферу облака. В качестве этих характеристик грозового облака рассмотрены: электрический заряд $q_{\Sigma}$, сосредоточенный в сферическом грозовом облаке заданного объема с мелкодисперсными заряженными включениями в виде твердых диэлектрических частиц с усредненной объемной плотностью; электрический потенциал $\varphi_{r}$ в сферическом объеме грозового облака заданного радиуса; электрическая энергия $W_{0}$, накопленная в сферическом объеме принятого грозового облака; амплитудно-временные параметры тока молнии в плазменном канале длинного воздушного искрового разряда грозового облака на землю. Полученные результаты будут способствовать возможности прогнозирования грозовой обстановки при минимальной исходной метеорологической информации, дальнейщему развитию природы атмосферного электричества, физики линейной молнии и решению глобальной проблемы молниезащиты объектов и обслуживающего их персонала. Библ. 12, рис. 2.

Ключевые слова: атмосферное электричество, грозовое облако, накопленный заряд, электрический потенциал и энергия облака, ток в канале разряда облака на землю, расчет, экспериментальные данные.

Introduction. One of the problematic tasks in the field of atmospheric electricity and lightning protection of terrestrial and near-earth air objects still remains one that is connected with the determination, with minimal initial information about the thunderstorm situation in the area of this or that territory of the planet studied by specialists (engineers and meteorologists) energy characteristics of the thundercloud cloud in the Earth's troposphere. Such characteristics of a thundercloud include: firstly, the total electric charge $q_{\Sigma}$ accumulated in such a cloud; secondly, the electric potential $\varphi_{r}$ in the volume of a thunderstorm cloud; thirdly, the electric energy $W_{0}$ accumulated by fine-dispersed inclusions (for example, small drops and water vapor, small granules and ice crystals and small solid dielectric particles $[1,2])$ of the atmospheric cloud under consideration in the «storm cloud - earth» electrostatic system; fourth, the probable amplitudetemporal parameters (ATPs) of the pulsed current $i_{L}(t)$ in the channel of the high-current discharge of a thunderstorm cloud to the ground or to the protected object. Their forecast of a possible thunderstorm threat to land-based objects and aircraft caught up in the area of the atmospheric cloud depend on these data. Knowledge of indicated energy characteristics of a thunderstorm cloud makes it possible to predict a thunderstorm situation in 
the investigated area of terrestrial land, and also in a certain way extends knowledge of people in the field of atmospheric electricity and the physics of a long air spark discharge (lightning) and the consequences of its (this high-current discharge) action on the protected objects and their environment. It should be noted that usually under a thundercloud, meteorologists understand a cumulonimbus cloud for which a number of critical conditions are met as indicated in [1]. As for the concept of the Earth's troposphere, it means the lower part of the earth's atmosphere, with a height of up to $11 \mathrm{~km}$ in temperate latitudes which contains $4 / 5$ of the entire mass of the atmosphere, almost all water vapor, and various kinds of clouds develop [1, 3]. In this connection, an approximate determination by calculation of the quantities $q_{\Sigma}, \varphi_{r}, W_{0}$ and ATPs of the discharge current $i_{L}(t)$ in the superhigh-voltage electrostatic system «thundercloud earth» in which the atmospheric cloud has even a canonical geometric shape and a simplified internal «stuffing» from a number of above-mentioned finedispersed inclusions, is an actual applied scientific and technical task of great importance in the world.

The goal of the paper is the calculation estimation of such basic energy characteristics of the «lightning cloud - ground» system as the charge $q_{\Sigma}$, the potential $\varphi_{r}$, the energy $W_{0}$ and the amplitude-temporal parameters of the pulsed current $i_{L}(t)$ in the channel of the long air spark discharge of the cloud to the earth.

1. Problem definition. For convenience in analyzing the distribution of atmospheric electricity in the Earth's troposphere, let us consider one of the special cases when the thundercloud has the shape of a sphere of radius $R_{0} \approx 985 \mathrm{~m}$ (Fig. 1), inside which, with an average volume density $N_{0} \approx 5 \cdot 10^{7} \mathrm{~m}^{-3}$, solid dielectric particles with a radius $r_{0} \approx 10 \cdot 10^{-6} \mathrm{~m}$ are mainly placed[1], each of which at the stage of formation of the cumulonimbus cloud obtained by electrifying in the warm ascending air streams of the Earth's atmosphere a negative electric charge of $q_{0} \approx-2.78 \cdot 10^{-16} \mathrm{C}$ and at the stage of formation of a thunderstorm cloud was freed from the covered them electrically neutral molecular dipoles of water [2]. The choice of the indicated numerical value of radius $R_{0}$ of the cloud was due to the fact that in order to simplify the calculations, as in [2], its initial calculation volume $V_{0} \approx 4 \cdot 10^{9} \mathrm{~m}^{3}$ was a rectangular prism with dimensions in a horizontal base of $1000 \mathrm{~m} \times 1000 \mathrm{~m}$ and a height of $4000 \mathrm{~m}$, the center of which was located at a height of $H_{0} \approx 3000 \mathrm{~m}$ above the flat surface of the Earth (see Fig. 1). According to [1] it is from such heights that the formation of cloud charges begins in the Earth's troposphere. Proceeding from the fact that in the adopted approximation $V_{0}=4 \pi R_{0}^{3} / 3=4 \cdot 10^{9} \mathrm{~m}^{3}$, and this numerical value of $R_{0}$ follows. As for the numerical values of the quantities $N_{0}$ and $r_{0}$, they were chosen by us on the basis of the experimental data given in [1]. The calculation determination in the cloud of the indicated numerical value of the charge $q_{0} \approx-2.78 \cdot 10^{-16} \mathrm{C}$ of solid dielectric particles of radius $r_{0} \approx 10 \cdot 10^{-6} \mathrm{~m}$ was carried out in [2], taking into account the theory of a double electric layer, the foundations of which are given in $[1,4]$. Individual charges $q_{0}$ of density $N_{0}$ determine in the cloud their averaged volume density $\sigma_{V} \approx q_{0} N_{0} \approx-1.39 \cdot 10^{-8} \mathrm{C} / \mathrm{m}^{3}$, uniformly distributed over its spherical volume $V_{0}$. Let normal atmospheric conditions be satisfied in the air gap of the «lightning cloud - earth» system (the air pressure is about $1.013 \cdot 10^{5} \mathrm{~Pa}$, and its temperature is $0{ }^{\circ} \mathrm{C}$. [4] It is required, taking into account these assumptions, in approximate form, to determine by calculations the required values of the accumulated by the thunderstorm cloud of the total charge $q_{\Sigma}$, the electric potential $\varphi_{r}$ in the spherical volume of the thunderstorm cloud, its electric energy $W_{0}$ and the ATPs of the discharge pulsed current $i_{L}(t)$ in the electrostatic system «thunder cloud - earth».

2. Calculation estimation the electric charge $q_{\Sigma}$ of a thunderstorm cloud. Taking into account the above assumptions at the stage of the formation of a thunderstorm cloud accompanied by the «liberation» of its separate numerous charges $q_{0}$ from electrically neutral molecular water dipoles [2], the total electric charge $q_{\Sigma}$ of the atmospheric cloud under consideration can be determined in the following form:

$$
q_{\Sigma}=q_{0} N_{0} V_{0} .
$$

From (1) at accepted initial data when $q_{0} \approx-2.78 \cdot 10^{-16} \mathrm{C}$, $N_{0} \approx 5 \cdot 10^{7} \mathrm{n}^{-3}$ and $V_{0} \approx 4 \cdot 10^{9} \mathrm{~m}^{3}$, it is following than in the considered case the value of $q_{\Sigma} \approx-55.6 \mathrm{C}$.

The modulus of the numerical value of the total electric charge $q_{\Sigma} \approx 55.6 \mathrm{C}$ in the considered lightning cloud obtained in accordance with (1) completely corresponds to the normalized charge $q_{L}=(50 \pm 10) \mathrm{C}$ for a short lightning strike with a pulsed discharge aperiodic current of a temporal shape $10 \mu \mathrm{s} / 350 \mu \mathrm{s}$ to ground technical facilities that satisfy III-IV lightning protection levels according to the requirements of the International Standard IEC 62305-1:2010 [5, 6].

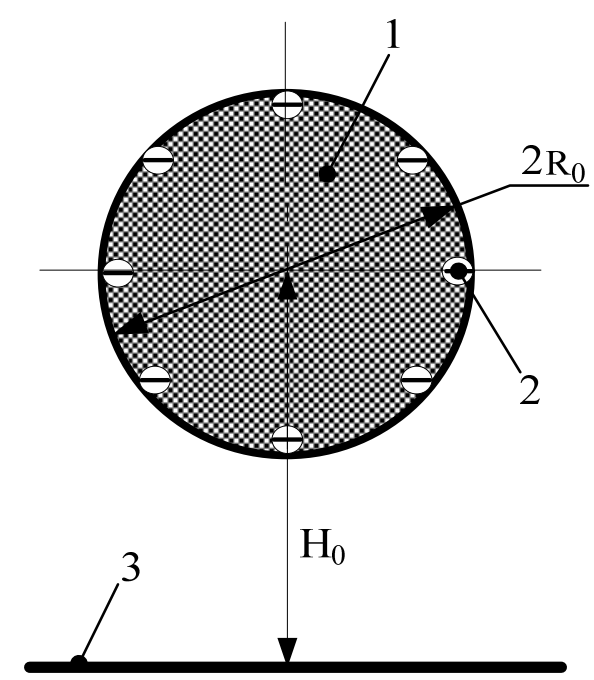

Fig. 1. Schematic view of a simplified calculation model of a negatively charged thunderstorm cloud of spherical shape located above the Earth's flat surface

(1 - cloud, 2 - electron, 3 - flat surface of the Earth)

In addition, we indicate that the used numerical value of the averaged volume charge density of the 
lightning cloud under investigation, defined as $\sigma_{V} \approx q_{0} N_{0} \approx-1.39 \cdot 10^{-8} \mathrm{C} / \mathrm{m}^{3}$, corresponds to known experimental data for the mean value of the space charge density in a thunderstorm cloud $[1,2]$.

3. Calculation estimation of the electric potential $\varphi_{r}$ of a thunderstorm cloud. Applying the approach given in [7] to finding in the cloud the values of the electric potential $\varphi_{r}$ for the radial distribution of the required potential $\varphi_{r}$ in the simplified model of the thundercloud, we obtain:

$$
\varphi_{r}=q_{\Sigma}\left(3 R_{0}^{2}-r^{2}\right) /\left(8 \pi \varepsilon_{0} R_{0}^{3}\right),
$$

where $r$ is the current radius in the spherical volume of the cloud; $\varepsilon_{0}=8.854 \cdot 10^{-12} \mathrm{~F} / \mathrm{m}$ is the electric constant[4].

From (2) at $r=0$ for the electric potential $\varphi_{r}=\varphi_{0}$ in the center of the assumed thunderstorm cloud, we find:

$$
\varphi_{0}=3 q_{\Sigma} /\left(8 \pi \varepsilon_{0} R_{0}\right) \text {. }
$$

At $r=R_{0}$ from (2) for the electric potential $\varphi_{r}=\varphi_{R}$ the following calculation relation follows on the outer surface of the sphere of a thunderstorm cloud:

$$
\varphi_{R}=q_{\Sigma} /\left(4 \pi \varepsilon_{0} R_{0}\right)
$$

Analysis of the above calculation expressions (3), (4) shows that the electric potential $\varphi_{0}$ in the center of the thunderstorm cloud is 1.5 times higher than the electric potential $\varphi_{R}$ acquired by the outer spherical surface of the cloud. Hence, the deep mechanism of charge "recharge» of the plasma channel of a long spark discharge of a thundercloud on the ground or a protected technical object becomes physically more understandable in the theory of atmospheric electricity. After all, at such a radial distribution in the thundercloud of the electric potential $\varphi_{r}$ in the case of an electric discharge in the «thunder cloud earth» system (see Fig. 1) of an air gap of length $\left(H_{0}-R_{0}\right)$ to compensate the decrease of the electric potential $\varphi_{R}$ on the outer surface of the cloud to it from inner zones of a cloud with a higher electric potential $\varphi_{r}$, the electric charges (in our case free electrons) will «leak» which replenish the carriers of the electric current $i_{L}(t)$ in the channel of the discharge itself.

Numerical estimation by (3), (4) of the electrical potentials inside and outside the thunderstorm cloud under consideration at $q_{\Sigma} \approx-55.6 \mathrm{C}$ and $R_{0} \approx 985 \mathrm{~m}$ indicates that in this case the required values are approximately equal by modulus to $\varphi_{0} \approx 759 \mathrm{MV}$ and $\varphi_{R} \approx 506 \mathrm{MV}$. From the quantitative data known to the author for the electric potential $\varphi_{r}$ of a thunderstorm cloud, only its numerical value of about $100 \mathrm{MV}$, given in [8], can be indicated.

In order to verify the reliability of the obtained electric potential value $\varphi_{R} \approx 506 \mathrm{MV}$ of the thunderstorm cloud under consideration, let us use a numerical estimation of the value of the electrostatic field strength $E_{R}$ near its outer spherical surface $\left(r \approx R_{0}\right)$. On the one hand, $E_{R} \approx \varphi_{R} / R_{0} \approx 513 \mathrm{kV} / \mathrm{m}$ [4]. On the other hand, in order to find $E_{R}$ in the investigated electrostatic case, we apply a more accurate analytic relation of the form $[2,7]$ :

$$
E_{R}=q_{\Sigma} /\left(4 \pi \varepsilon_{0} R_{0}^{2}\right) .
$$

From (5) at $q_{\Sigma} \approx 55.6 \mathrm{C}$ and $R_{0} \approx 985 \mathrm{~m}$ we find that $E_{R} \approx 515 \mathrm{kV} / \mathrm{m}$. It is evident that both numerical values given for $E_{R}$ practically coincide. In this connection, we can speak of the efficiency of the calculated ratios (1), (4) that determine the total charge $q_{\Sigma}$ in the adopted thunderstorm cloud model and the electric potential $\varphi_{R}$ of the outer spherical surface of the cloud under investigation. By the way, the value of $E_{R}$ by (5) is the largest in the radial distribution of the electrostatic field strength in the spherical volume $V_{0}$ of the cloud. As is well known, for this high $E$-field according to a relation of the form $[2,7]$ :

$$
E_{r}=q_{\Sigma} r /\left(4 \pi \varepsilon_{0} R_{0}^{3}\right),
$$

at $r=0$ the strength $E_{r}$ will be equal to zero (at $r=R_{0}$ (6) becomes (5) and determines the level of the $E$-field on the outer surface of this cloud).

The data presented for the radial distribution of the electrostatic field strength $E_{r}$ in the «storm cloud - earth» system unequivocally indicate that in the case of a homogeneous (in the composition [3]) character of the change in the carriers of electricity in the spherical volume $V_{0}$ of the assumed thunderstorm cloud, the development of electron avalanches [1,8] which are the forerunner of the appearance in our system of lightning (spark breakdown in the troposphere of the Earth of a long air gap) will always start from the outer surface of the cloud. Note that the indicated numerical value of $E_{R} \approx 515 \mathrm{kV} / \mathrm{m}$ at the accepted atmospheric conditions approaches the critical $E$-field value corresponding to the pre-breakdown stage of processes in the long air gap our system of the length $\left(H_{0}-R_{0}\right)$ of our system $[1,8]$.

4. Calculation estimation of the electrical energy $W_{0}$ of a thunderstorm cloud. Preliminary calculation estimations of the numerical values of the electric energy $W_{0}$ accumulated in the storm cloud under investigation revealed the presence of a number of features in its determination. Thus, it turned out that the direct application of the principles and formulas from [9] for its electric capacitance to the calculation system «thunder cloud - earth» (see Fig. 1) leads to erroneous results in calculating the values of the $W_{0}$ energy of a thunderstorm cloud. In order to demonstrate the results obtained with respect to the energy $W_{0}$ with such a calculated approach, we first start from the fact that at the electric potential $\varphi_{R}$ of the cloud found above (in Section 3 ) and the a priori zero earth electrical potential $\left(\varphi_{E}=0\right)$ for calculating of the electrical energy $W_{0}$ for the «storm cloud - earth» calculation system that is used, it remains to determine only the value of its electrical capacitance. The «direct» definition in the case under consideration $\left(H_{0} / R_{0} \approx 3.04\right)$ of its electrical capacitance $C_{0}$, according to the recommended [9] for the inequality $H_{0} / R_{0}>1.5$ an approximate formula of the form:

$$
C_{0}=2 \pi \varepsilon_{0} / \ln \left(2 H_{0} / R_{0}\right),
$$

leads to significantly lowered values of the electrical capacitance in the calculation system «thunder cloud - 
earth». For example, assuming the initial data $H_{0} \approx 3000 \mathrm{~m}$ and $R_{0} \approx 985 \mathrm{~m}$, according to (7), the value of $C_{0}$ is approximately $C_{0} \approx 30.8 \cdot 10^{-12} \mathrm{~F}$. Therefore, the value $W_{0} \approx C_{0} U_{0}^{2} / 2$ [4], where $U_{0}=\left(\varphi_{R}-\varphi_{E}\right)$ is the difference between the electrical potentials of a thunderstorm cloud and a flat ground surface, assumes a numerical value of only $3.94 \mathrm{MJ}$ for $U_{0} \approx 506 \mathrm{MV}$ and the huge volume $V_{0} \approx 4 \cdot 10^{9} \mathrm{~m}^{3}$ of a thunderstorm cloud used by us. The reason for this is that (7) takes into account only the distribution of electric charge along the outer surface of the calculated sphere of radius $R_{0}$. It does not take into account the effect of the electric charge distributed with volume density $\sigma_{V} \approx q_{0} N_{0}$ in volume $V_{0}=4 \pi R_{0}^{3} / 3$ of this sphere. In this regard, the value of the electric energy $W_{0}$ of a thunderstorm cloud is recommended to be determined by the following approximate relationship:

$$
W_{0} \approx 0,5 C_{E} U_{0}^{2},
$$

where $C_{E} \approx q_{\Sigma} / U_{0}$ is the equivalent capacitance of the superhigh-voltage system «thunder cloud - earth».

It should be noted that when using (8) a some error is introduced into the approximate calculation of $C_{E}$ and $W_{0}$ values, due to the previously described the corresponding radial distribution of the electric potential $\varphi_{r}$ over the spherical volume of the received thunderstorm cloud. However, this error is incommensurable small in comparison with the error introduced by (7) into the calculation of the electric capacitance and electric energy $W_{0}$ in our system «thunder cloud - earth».

From (8) at $q_{\Sigma} \approx-55.6 \mathrm{C}$ и $U_{0} \approx-506 \mathrm{MV}$, we find that with the recommended author's approach for the system «thunder cloud - earth» under consideration, the value of its equivalent electric capacitance $C_{E}$ will assume a numerical value of about $1.1 \cdot 10^{-7} \mathrm{~F}$, and the value of electric energy accumulated in it is $W_{0} \approx 14.1 \cdot 10^{9} \mathrm{~J}$ (as we see, it is almost 3578 times larger than with the use of formula (7) in calculating $C_{0}$ and $W_{0}$ ). The author currently does not have quantitative data for $W_{0}$ by other researchers of atmospheric electricity in the world. It can only be assumed that if the values of the total charge $q_{\Sigma}$ by (1) and the electric potential $\varphi_{R}$ by (4) are found correctly (we have given the above fairly convincing electrophysical justifications of these calculations), then the approximate determination by (8) of the value of the electric energy $W_{0}$ of the thunderstorm cloud is also correct.

5. Calculation estimation of the ATP of current $i_{L}(t)$ in the thunderstorm discharge channel on the earth. For this estimation, with reference to the discharge circuit of the capacitance $C_{E}$ of the thunderstorm cloud through the plasma channel in the air to the earth, we use the classical electrical engineering approach characteristic for electromagnetic processes in the $R L C$ circuit [10]. First, we estimate the numerical value of the inductance $L_{k}$ of a cylindrical plasma channel with the radius $r_{k}$ of a high-current spark discharge of a thunderstorm cloud in the air gap of length $l_{k} \approx\left(H_{0}-R_{0}\right)$ to the earth according to the following formula [11]:

$$
L_{k}=(2 \pi)^{-1} \mu_{0} l_{k}\left[\ln \left(2 l_{k} / r_{k}\right)-1\right],
$$

where $\mu_{0}=4 \pi \cdot 10^{-7} \mathrm{H} / \mathrm{m}$ is the magnetic constant [4].

From (9), at $l_{k} \approx\left(H_{0}-R_{0}\right) \approx 2015 \mathrm{~m}$ and $r_{k} \approx 11 \cdot 10^{-3} \mathrm{~m}$ [12] it follows that in our case the concentrated inductance $L_{k}$ of the thunderstorm cloud discharge channel on the earth will take a value numerically equal to about $4.76 \mathrm{mH}$. When evaluating the numerical value of the active resistance $R_{k}$ of a cylindrical lightning air discharge channel, we proceed from the fact that the line active resistance $R_{k 0}$ of the investigated high-current channel, according to the calculation-experimental data from [12] for the repetitive pulsed $D$-component of the artificial lightning current of the amplitude $I_{m D} \approx-92.3 \mathrm{kA}$ (Fig. 2, where $\mathrm{t} t_{m D} \approx 15 \mu \mathrm{s}$ is the time corresponding to the first amplitude $I_{m D}$ of the current) is numerically about $0.92 \Omega / \mathrm{m}$. As a result, for the active resistance $R_{k}$ of the thunderstorm plasma channel of the investigated cloud to the earth (see Fig. 1) we find that $R_{k} \approx R_{k 0} l_{k} \approx 0.92 \Omega \cdot \mathrm{m}^{-1} \times$ $\times 2015 \mathrm{~m} \approx \approx 1.85 \mathrm{k} \Omega$. It is seen that in the case under consideration the inequality $R_{k}>2\left(L_{k} / C_{E}\right)^{1 / 2}$ is satisfied for the electrical parameters $R_{k}, L_{k}$ and $C_{E}$ of the discharge circuit under consideration. This means that an aperiodic current pulse $i_{L}(t)$ will flow in the lightning current channel $[10,12]$.

For the ATP of the discharge current $i_{L}(t)$ at an aperiodic law of its variation with time $t$, the following calculation relation can be used $[10,12]$ :

$$
i_{L}(t)=U_{0}\left[\left(\alpha_{2}-\alpha_{1}\right) L_{k}\right]^{-1}\left[\exp \left(-\alpha_{1} t\right)-\exp \left(-\alpha_{2} t\right)\right],
$$

where $\alpha_{1}, \alpha_{2}$ are the pulsed current shape coefficients equal to $\alpha_{1}=\delta-\left(\delta^{2}-\omega_{0}{ }^{2}\right)^{1 / 2}$ and $\alpha_{2}=\delta+\left(\delta^{2}-\omega_{0}^{2}\right)^{1 / 2} ; \delta=R_{k} /\left(2 L_{k}\right)$ is the attenuation coefficient of discharge current; $\omega_{0}=\left(L_{k} C_{E}\right)^{-1 / 2}$ is the own circular frequency of the discharge current of a cloud.

The time $t_{m L}$ corresponding to the amplitude $I_{m L}$ of the lightning current of the discharge in accordance with (10) will be equal to the analytical relation known in electrical engineering [10]:

$$
t_{m L}=\ln \left(\alpha_{2} / \alpha_{1}\right) /\left(\alpha_{2}-\alpha_{1}\right) .
$$

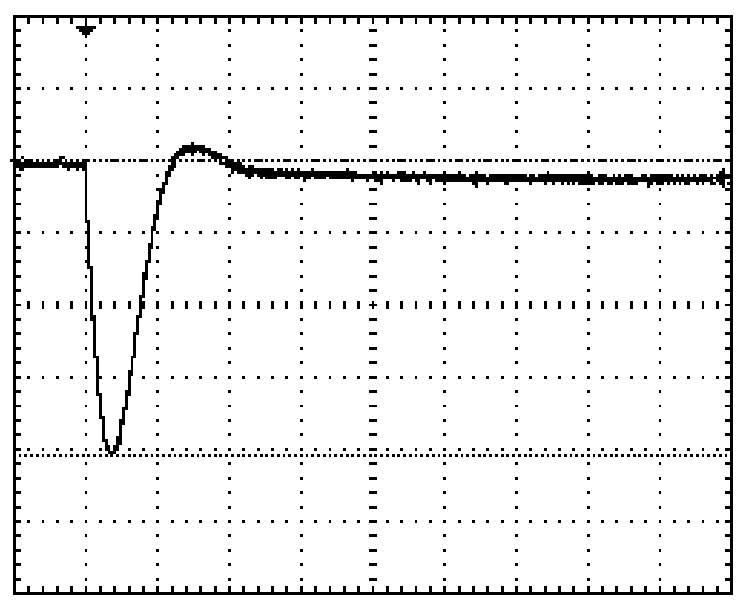

Fig. 2. Typical oscillogram of the $D$ - component of the current Of artificial lightning $\left(I_{m D} \approx-92.3 \mathrm{kA} ; t_{m D} \approx 15 \mu \mathrm{s}\right.$, vertical scale $22.52 \mathrm{kA} /$ cell, horizontal scale $-50 \mu \mathrm{s} /$ cell $)$ obtained in the high-current discharge circuit of the high-voltage lightning current generator УИТОМ-1 [12] 
For the obtained initial data $R_{k} \approx 1.85 \mathrm{k} \Omega$, $L_{k} \approx 4.76 \mathrm{mH}$ and $C_{E} \approx 110 \mathrm{nF}$, we see that in the case under consideration: $\delta \approx 1.94 \cdot 10^{5} \mathrm{~s}^{-1} ; \omega_{0} \approx 43.7 \cdot 10^{3} \mathrm{~s}^{-1}$; $\alpha_{1} \approx 5 \cdot 10^{3} \mathrm{~s}^{-1} ; \alpha_{2} \approx 3.83 \cdot 10^{5} \mathrm{~s}^{-1} ; t_{m L} \approx 11.47 \mu$ s (see Fig. 2 , where the experimental time for the pulse amplitude of the artificial lightning current was about $15 \mu \mathrm{s}$ ). At $U_{0} \approx-506 \mathrm{MV}$ and $t_{m L} \approx 11.47 \mu \mathrm{s}$, the calculated value of the amplitude of the lightning current for the investigated case according to (10) will be approximately $I_{m L} \approx-262.1 \mathrm{kA}$. The obtained quantitative values for $t_{m L}$ and the amplitude $I_{m L}$ of the current in the discharge channel of the assumed thunderstorm cloud to earth are well correlated with the ATPs of the pulse current characteristic for short strokes of the linear lightning to ground objects satisfying the I level of their lightning protection according to the stringent requirements of the International Standard IEC 62305-1:2010 [5, 6]. As for the duration $\tau_{p}$ of the aperiodic lightning current pulse at the level $0.5 I_{m L}$, for our case it is approximately equal to $\tau_{p} \approx 0,7 R_{k} C_{E} \approx 142.4 \mu \mathrm{s}$. Thus, with minimal information on the electromagnetic situation in the zone of formation and development of a thunderstorm cloud (only in terms of its approximate dimensions and height of placement above the Earth's surface), experts can reasonably predict a thunderstorm «picture» for the superhigh-voltage electrophysical system «thunder cloud - earth» under consideration.

\section{Conclusions.}

1. It is shown that by engineers and meteorologists a spherical cloud model with an outer radius $R_{0}$ and a volume $V_{0}=4 \pi R_{0}{ }^{3} / 3$ can be adopted as a simplified calculation model of a thundercloud cloud containing distributed over its spherical volume with an average density of $N_{0} \approx 5 \cdot 10^{7} \mathrm{~m}^{-3}$ negatively electrified in the warm ascending air flows of the Earth's troposphere, small solid dielectric particles with a radius of $r_{0} \approx 10 \cdot 10^{-6}$ $\mathrm{m}$ and a charge of $q_{0} \approx-2,78 \cdot 10^{-16} \mathrm{C}$. Varying the numerical values of the radius $R_{0}$ and, correspondingly, the volume $V_{0}$ of such a thundercloud cloud, one can also change its basic energy characteristics within a wide range corresponding to the normative and technical documents in force in the world.

2. An example of a thunderstorm cloud of the Earth's troposphere of radius $R_{0} \approx 985 \mathrm{~m}$ and volume $V_{0} \approx 4 \cdot 10^{9} \mathrm{~m}^{3}$ at $H_{0} \approx 3000 \mathrm{~m}$ demonstrates the possibilities of the proposed approach in the field of atmospheric electricity investigations for the approximate determination by specialists of the modules of such its energy characteristics as the total electric charge $q_{\Sigma} \approx 55.6 \mathrm{C}$, electric potential at the center $\varphi_{0} \approx 759 \mathrm{MV}$ and on the outer surface $\varphi_{R} \approx 506 \mathrm{MV}$ of the cloud, accumulated by fine-dispersed inclusions of the cloud electric energy $W_{0} \approx 14.1 \mathrm{GJ}$ and ATPs of the aperiodic impulse current $i_{L}(t)$ in the plasma channel of the long air spark discharge of the cloud to earth $\left(I_{m L} \approx 262.1 \mathrm{kA} ; t_{m L} \approx 11.5 \mu \mathrm{s}\right.$; $\left.\tau_{p} \approx 142.4 \mu \mathrm{s}\right)$. The obtained quantitative data for $q_{\Sigma}, \varphi_{R}, W_{0}$ and ATPs of lightning impulse current on the earth's surface satisfy a number of requirements of the
International Standard IEC 62305-1:2010 for short strokes of linear lightning to ground objects.

3. The results obtained will contribute to the possible fulfillment by engineers and meteorologists of the prediction of the electromagnetic situation in the area of formation and development in the Earth's troposphere of a real thunderstorm cloud, previously reduced by the volume of $V_{0}$ occupied by it to an equivalent storm cloud of spherical shape with radius $R_{0}$. This approach, thanks to the developed physical and mathematical apparatus, makes it possible in an approximate form to find the indicated basic energy characteristics $\left(q_{\Sigma}, \varphi_{R}, W_{0}\right.$ and ATPs of the channel current) of an equivalent thundercloud cloud and opens up certain new possibilities in the world practice of solving the actual problems of lightning protection of ground objects and in-flight aircraft that have found themselves in a hazardous zone of high electromagnetic influence on their electrical equipment (first of all, on their low-current electronics) of a thunderstorm cloud with its huge in terms of numerical indicators energy characteristics.

\section{REFERENCES}

1. Bortnik I.M., Beloglovskiy A.A., Vereshchagin I.P., Vershinin Yu.N., Kalinin A.V., Kuchinskiy G.S., Larionov V.P., Monastyrskiy A.E., Orlov A.V., Temnikov A.G., Pintal' Yu.S., Sergeev Yu.G., Sokolova M.V. Elekrophizicheskie osnovy techniki vysokih naprjazhenij [Electrophysics bases of technique of high voltage]. Moscow, Publishing house of MEI, 2010. 704 p. (Rus).

2. Baranov M.I. New hypothesis and electrophysics nature of additional mechanisms of origin, accumulation and division of electric charges in the atmospheric clouds of Earth. Electrical engineering \& electromechanics, 2018, no.1, pp. 46-53. doi: 10.20998/2074-272X.2018.1.07.

3. Bol'shoj illjustrirovannyj slovar' inostrannyh slov [Large illustrated dictionary of foreign words]. Moscow, Russkie slovari Publ., 2004. 957 p. (Rus).

4. Kuz'michev V.E. Zakony i formuly fiziki [Laws and formulas of physics]. Kiev, Naukova Dumka Publ., 1989. 864 p. (Rus).

5. IEC 62305-1: 2010 «Protection against lightning. Part 1: General principles». Geneva, IEC Publ., 2010.

6. Baranov M.I., Koliushko G.M., Kravchenko V.I., Rudakov S.V. A generator of aperiodic current pulses of artificial lightning with a rationed temporal form of $10 \mu \mathrm{s} / 350 \mu \mathrm{s}$ with an amplitude of $\pm(100-200) \mathrm{kA}$. Instruments and Experimental Techniques, 2015, vol.58, no.6, pp. 745-750. doi: 10.1134/s0020441215060032.

7. Javorskij B.M., Detlaf A.A. Spravochnik po fizike [Handbook of physics]. Moscow, Nauka Publ., 1990. 624 p. (Rus).

8. Brzhezitskiy V.A., Bilyy I.V., Boyko N.I., Gul' V.I., Gurin A.G., Il'enko O.S., Isakova A.V., Kondra B.M., Kopshin V.A., Kravchenko V.I., Naboka B.G., Protsenko O.R., Rudakov V.V., Khimenko L.T., Khominich V.I., Shostak V.A., Yanishevskiy V.I. Tehnika i elektrophizika vysokih naprjazhenij [Technics and Electrophysics of High Voltages]. Kharkiv, Tornado Publ., 2005. 930 p. (Ukr).

9. Iossel' Yu.Ya., Kochanov E.S., Strunskiy M.G. Raschet elektricheskoj emkosti [Calculation of electric capacity]. Leningrad, Energoizdat Publ., 1981. 288 p. (Rus). 
10. Neyman L.R., Demirchyan K.S. Teoreticheskie osnovy elektrotekhniki. V 2-kh t. T. 1 [Theoretical bases of electrical engineering. In 2 vols. Vol. 1]. Leningrad, Energoizdat Publ., 1981, p. 536. (Rus).

11. Knopfel' G. Sverkhsil'nye impul'snye magnitnye polia [Ultra strong pulsed magnetic fields]. Moscow, Mir Publ., 1972. 391 p. (Rus).

12. Baranov M.I. Izbrannye voprosy elektrofiziki. Tom 3: Teorija i praktika elektrofizicheskih zadach [Selected topics of Electrophysics. Vol. 3: Theory and practice of electrophysics tasks]. Kharkiv, Tochka Publ., 2014. 400 p. (Rus).

Received 19.02.2018

How to cite this article:

Baranov M.I. Power descriptions of a storm cloud of troposphere of Earth: features of their calculation and applied utilization. Electrical engineering \& electromechanics, 2018, no.3, pp. 37-42. doi: 10.20998/2074-272X.2018.3.05.
M.I. Baranov, Doctor of Technical Science, Chief Researcher, Scientific-\&-Research Planning-\&-Design Institute «Molniya» National Technical University «Kharkiv Polytechnic Institute», 47, Shevchenko Str., Kharkiv, 61013, Ukraine, phone +380 577076841 ,

e-mail: baranovmi@kpi.kharkov.ua 